\title{
OS IMPACTOS DA PREPARAÇÃO DOS ESTUDANTES NO ENSINO TÉCNICO PARA O MERCADO DE TRABALHO
}

\section{ARTIGO DE REVISÃO}

MARCIANO, Carina Fernanda ${ }^{1}$

SCATOLIN, Henrique Guilherme ${ }^{2}$

MARCIANO, Carina Fernanda. SCATOLIN, Henrique Guilherme. Os impactos da preparação dos estudantes no ensino técnico para o mercado de trabalho. Revista Científica Multidisciplinar Núcleo do Conhecimento. Ano 05, Ed. 11, Vol. 23, pp. 137-155. Novembro de 2020. ISSN: 2448-0959, Link de acesso: https://www.nucleodoconhecimento.com.br/psicologia/impactos-dapreparacao

\section{RESUMO}

O ensino técnico no Brasil, atualmente, trata-se de um campo amplamente difundido no cenário nacional. Assim, este trabalho tem como objetivo uma reflexão sobre os impactos da formação técnica no mercado de trabalho. Neste sentido, como o sistema de ensino das escolas técnicas do Brasil impacta a inserção do estudante no mercado de trabalho? O estudo consiste em uma revisão bibliográfica, com base teórica em Karl Marx, Simone Weil, Yves Clot, entre outros autores. Procura-se discutir, de maneira crítica, com diferentes olhares teóricos, temas de grandes relevâncias sociais, pensando o campo educacional, político e do trabalho. Assim, as discussões em torno do trabalho e os reflexos no trabalhador tornam-se grande ponto para reflexão. Percebe-se que neste contexto o alunostá sendo preparado no ensino

1 Pós-Graduada em Psicologia Organizacional e do Trabalho. Graduação em Psicologia.

2 Orientador. Doutorado em Psicologia (Psicologia Clínica). Mestrado em Psicologia (Psicologia Clínica). Graduação em Psicologia. 
técnico para um processo de execução de tarefas rápido, e não necessariamente precisa refletir sobre os acontecimentos do ambiente de trabalho, pois as tarefas estão pré-moldadas e o conteúdo obrigatório é objetivo. Diante disso, a inquietação da autora desta pesquisa com a defasagem no cenário político, social e educacional brasileiro provocou um olhar voltado ao campo em que os estudantes saem do ensino técnico para o mercado de trabalho, pois durante o percurso estão atreladas grandes questões sociais, inclusive no campo da atuação profissional. Este artigo não buscou generalizar os estudantes do ensino técnico, mas apresentar possíveis impactos no trabalhador neste contexto. Assim, com o término da pesquisa, observa-se uma forte relação entre o surgimento do ensino técnico como uma necessidade de qualificação da mão-de-obra no âmbito empresarial.

Palavras-chave: Psicologia do trabalho, ensino técnico, Educação.

\section{INTRODUÇÃO}

O presente artigo surge com a inquietação da autora deste trabalho com uma defasagem no cenário político, social e educacional brasileiro, que provocou um olhar voltado ao campo de formação do ensino técnico no mercado de trabalho, visto que durante o percurso estão atreladas questões sociais, assim como citado anteriormente, pois compreende-se que este momento se torna imprescindível para um impacto no cenário nacional, inclusive no campo do trabalho. Assim, este artigo tem como objetivo uma reflexão sobre os impactos da formação de estudantes no ensino técnico para o mercado de trabalho.

Desta forma, será utilizado na pesquisa autores que discutem o campo do trabalho apresentando, inicialmente, um breve histórico do trabalho com suas atribuições e significações, para posteriormente apresentar o mercado a qual este artigo refere-se. Adiante, apresenta-se autores que discorrem um breve histórico da educação do ensino técnico que compreende aos objetivos deste trabalho. Por fim, o último tópico apresentará os possíveis desdobramentos dos impactos que podem ser proporcionados pelo ensino técnico. 
Assim, compreende-se que a educação profissional no Brasil, segundo Cordeiro et al. (2009), surgiu atrelada aos interesses econômicos empresariais, pois inicialmente, a demanda era direcionada a formação de jovens aprendizes para as indústrias, situação que prevalece uma predominância no ensino técnico e um distanciamento de uma formação integral do estudante, pois o ensino voltava-se as necessidades da mão de obra nas indústrias, ou seja, perde-se o conteúdo direcionado as necessidades do cidadão para atender ao mercado de trabalho.

Com isso, a educação profissional é tomada e direcionada por um desenho das escolas técnicas, segundo Cordeiro et al. (2009). Diante dessa afirmação, pode-se compreender que o trabalho, neste contexto de formação técnica, por vezes, deixa de ser direcionado as necessidades do sujeito, assim como afirma Marx (2014), o jogo de forças dentro das empresas esgota o trabalhador ao extremo, assim, suprime suas atividades produtivas e apreende todas as atividades que poderiam ser livres do trabalhador, pois as máquinas ao invés de libertar os sujeitos, os transformam em objetos de seu interesse.

Neste contexto o trabalhador, muitas vezes, torna-se submisso aos comandos do empregador, como Weil (1996) escreve, quando o trabalhador está esgotado da sua função o pensamento é obrigado a passar de um momento para o outro sem, necessariamente, se agarrar ao passado e nem ao futuro, assim, ambos não precisam estar conectados.

No contexto apresentado, pode-se referir que, por vezes, o trabalhador perde o sentido da produção, pois o trabalho não, necessariamente, faz sentido. Deste modo, segundo Clot (2006), as atividades que o sujeito é impedido de produzir, como também seu direito de agir diante de uma situação, pode causar sofrimento no ambiente de trabalho. Ainda pode-se acrescentar que esse contexto pode acarretar uma não satisfação do trabalho, que segundo Bendassoli (2009), a não satisfação pode ocasionar uma tensão e mal estar no trabalho.

Diante disso, o ensino técnico pode causar, por vezes, um direcionamento no trabalho que produz ao sujeito um impedimento ao enriquecimento subjetivo, produzindo 
impactos frente a relação entre homem e trabalho. Neste sentido, o artigo tem como problemática a seguinte questão: "Quais os possíveis impactos a formação técnica pode produzir no trabalhador?".

\section{METODOLOGIA}

A pesquisa trata-se de um estudo com o método de Revisão Bibliográfica[3], pois permite uma liberdade para que sejam reunidos dados para posterior análise e interpretação, assim como conhecer produções na área e direcionar a pesquisa para um trabalho inovador. Mancini e Sampaio (2006, p. 1) apresentam o estudo como:

[...] caracterizadas pela análise e pela síntese da informação disponibilizada por todos os estudos relevantes publicados sobre um determinado tema, de forma a resumir o corpo de conhecimento existente e levar a concluir sobre $o$ assunto de interesse.

Para encontrar os materiais bibliográficos da pesquisa, inicialmente, aconteceu uma busca na base de dados Scielo, da qual foi pesquisado os descritores: Psicologia and Trabalho, apareceram 3.951 resultados, filtrou-se para português resultou: 2.996, filtrou-se para tipo de literatura: artigo, psicologia social e ciências humanas, resultou em 800 trabalhos, posteriormente foram selecionados os artigos de acordo com o interesse pelos títulos e resumos.

Ocorreu também, na base de dados Scielo, a busca com os descritores: Ensino or Técnico e Educação, 20.000 resultados. Filtrou-se para Brasil, português, ciências humanas, artigo, educação e pesquisa educacional, psicologia e psicologia multidisciplinar, resultando em: 3.000 artigos, que foram selecionados via resumos. Como critério de exclusão, foram utilizados os descritores que não condiziam com o tema.

Seguindo orientações do professor/orientador do trabalho, aconteceu uma busca virtual, inicialmente, no banco de dados da biblioteca "Duse Rüegger Ometto" Instituição de Ensino FHO - Uniararas. Com títulos do tema em questão: Psicologia do Trabalho, Educação, Ensino técnico no Brasil, dentre outros temas pertinentes a pesquisa. Assim, livros e periódicos foram encontrados para embasar a pesquisa. 
Os principais teóricos que impulsionam as reflexões do trabalho, advêm de alguns textos de autores como Karl Marx, especificamente o livro "O Capital: Crítica da economia política" (2006), Simone Weil, utilizado o livro "A condição operária e outros estudos sobre a opressão." (1996), Pedro Bendassolli com o livro "Psicologia e trabalho: apropriações e significados." (2009), Theodor Adorno, especificamente o capítulo Educação após Auschwitz. In. Educação e emancipação. Dentre outros autores que, também dedicaram suas reflexões ao tema em questão.

Entretendo, é importante ressaltar que o corpo teórico do trabalho pode aumentar no decorrer da pesquisa, pois dependerá da necessidade da autora em se amparar em outros estudos para levantamento de dados.

Assim, tal pesquisa é pertinente e promissora para refletir sobre a formação dos estudantes no ensino técnico e os impactos no mercado de trabalho, ou seja, estamos nos referindo a um tema que interfere diretamente na formação do outro e vice-versa.

\section{FUNDAMENTAÇÃO TEÓRICA}

Neste momento será percorrido brevemente o percurso histórico do trabalho e suas atribuições em diferentes períodos da história para, posteriormente, apresentar o mercado de trabalho que refere-se este artigo, junto as contribuições apresentadas pela psicologia que será discutido adiante.

O trabalho assume diferentes fases ao decorrer da história, produzindo diversas significações para o trabalhador e sobre a compreensão cultural do trabalho. $\mathrm{Na}$ antiguidade clássica por volta do século $V$ a.c.,

O trabalho obedeceu a duas vertentes básicas: as elites dominantes ocupavam-se exclusivamente do trabalho intelectual, artístico, especulativo ou político. De outro lado, as funções consideradas subalternas por sua natureza rústica e penosa ("trabalho braçal") eram desempenhadas pela mão de obra escrava, obtida nas guerras de conquista. Os vencidos eram transformados em escravos. (ORNELLAS; MONTEIRO, 2006, p. 552, 553) 
Percebe-se neste cenário que a classe dominante da elite possuía controle sobre o trabalhador, já que os sujeitos que não tinham condições sociais para assumir as atividades nobres pertencentes a elite. Esses possuíam apenas o direito de um lugar social desfavorecido e sem opções de escolhas: a sobrevivência também era um trabalho diário.

Posteriormente, por volta do século VI a.c., podemos encontrar a servidão do Sistema Feudal "em que os senhores feudais davam proteção militar e política aos servos, que não eram livres, mas, ao contrário, tinham de prestar serviços na terra do senhor feudal" (MARTINS, 200, p. 169). Ainda nessa época, existia controle sobre o trabalhador, suas condições os colocavam em um lugar de submissão e degradação, visto que o trabalho braçal ainda era considerado como um castigo em que a classe nobre não precisava submeter-se.

Após anos de degradação e submissão de muitos trabalhadores ao sistema de poder da classe dominante, gerenciado pela nobreza, da qual a igreja tem grande parte nesse processo de imposição do poder-saber. Martins (2000), menciona que por volta do século XIV em um terceiro plano acontece as corporações de ofício que envolvem três principais papéis: os mestres, companheiros e os aprendizes que se referiam:

Os mestres eram os proprietários das oficinas, que já tinham passado pela prova da obra-mestra. Os companheiros eram trabalhadores que percebiam salários dos mestres. Os aprendizes eram os menores que recebiam dos mestres o ensino metódico do ofício ou profissão. (MARTINS, 2000, p. 170)

O mesmo autor ainda acrescenta que, embora neste momento percebe-se uma maior autonomia do trabalhador em relação a outros períodos, ainda que o trabalho estava voltado a corporação e produção, sem conferir proteção ao trabalhador. Adiante, acrescenta-se que neste período era necessário lidar com uma adaptação do sujeito aos meios de produção, sendo necessário um processo "para trabalhar com máquinas, o trabalhador tem de começar sua aprendizagem muito cedo, a fim de adaptar seu próprio movimento ao movimento uniforme e continuo de um autômato [...]". (MARX, 2014, p. 480) Esse trabalho acontecia por um viés de imposição e saber sobre os meios de produção 
Posteriormente as corporações de ofício foram suprimidas pelo período Renascentista, durante os séculos XV e XVI, que segundo Ornellas e Monteiro (2006) deram espaço para o humanismo e o sujeito passou a ser o centro, protagonista de sua história. Neste contexto, ideias progressistas que contrapunham-se as concepções medievas de degradação humana, iniciam-se assim, novos tempos de esperança. Junto disso, "estavam tomando forma as circunstâncias que dariam origem ao mais importante evento do mundo do trabalho: a Revolução Industrial." (ORNELLAS; MONTEIRO, 2006, p. 553).

A revolução industrial apresentou grande importância no mundo do trabalho, como citado acima, cabe fazer um adento as suas três fazes: primeira revolução industrial, segunda revolução industrial e terceira revolução industrial.

Com início no século XVIII, na Inglaterra, segundo Pochmann (2016) a primeira revolução industrial marca o momento de produção têxtil, com a passagem da manufatura para o sistema fabril e as máquinas a vapor, a "farta produção de matérias primas [...] e o uso crescente das novas máquinas de tear potencializou a indústria metalúrgica e de mineração de carvão". (POCHMANN, 2016, p. 26). A segunda revolução industrial iniciou, por volta do século XIX, marcada com o grande progresso no campo científico e tecnológico, como esclarece Pochmann (2016) "[...] a internalização de novos produtos e de grandiosa escala de produção nos setores da energia elétrica, química, petróleo, motor a combustão, aço, entre outros" (p. 32), ainda segundo o mesmo autor, os métodos Taylorismo e Fordismo de produção também marcam esse momento, com as esteiras rolantes e a geração de lucro. A terceira revolução industrial começou no século XX, marcada por grandes avanços científicos e tecnológicos,

[...] constitui um processo difuso que repercute na dimensão cultural; o chamado pós-modernismo, influencia a arte e os costumes. No que diz respeito à política e à economia gerou o chamado neoliberalismo e a era da globalização. Essa transformação no modo de produção ocorre simultaneamente na organização do Estado e no processo de trabalho nos setores: primário (agropecuária, extração de minérios), secundário (indústria, pesquisa, informática) e terciário (serviços), sendo este último o âmbito do setor saúde. (MEDEIROS; ROCHA, 2004, p. 400) 
Diante disso segundo Sampaio (1998) com a revolução industrial, já consolidada no século $\mathrm{XX}$, a Psicologia entra em cena para tomar parte de um cenário em que o Taylorismo e a ideologia administrativa assume o contexto do trabalho, obtendo aumento de produção com maior controle sobre o trabalho e aumento da produção em massa. Percebe-se que neste momento a produção ágil assume um primeiro plano no mundo do trabalho.

Neste contexto Sampaio (1998) caracteriza três fases da Psicologia no mundo do trabalho que será, brevemente, citado. A primeira fase, a Psicologia da Indústria, "surge atrelada aos interesses das indústrias, instrumentalizando alguns pressupostos do Taylorismo" (SAMPAIO, 1998, p. 20). Com isso, podemos dizer que a produtividade e o esforço do trabalhador entram em ascensão, pois a produção poderia determinar a permanência do sujeito na indústria, o papel da Psicologia neste contexto era aplicações de testes e os estudos sobre o campo do trabalho, visando aumento da produção. (SAMPAIO, 1998)

A segunda fase é a Psicologia Organizacional que "surgiu à medida que os psicólogos deixaram de estudar apenas os postos de trabalho para contribuir também na discussão das estruturas da organização" (SAMPAIO, 1998, p. 23). Sampaio (1998) acrescenta que a Psicologia Organizacional não trata-se de uma brusca ruptura com a Psicologia Industrial, pois houve uma maior atenção ao campo de estudo das organizações, ou seja, amplia os estudos na área, percebe-se que neste momento volta-se um olhar para as capacitações e desenvolvimento no trabalho. Os Recursos Humanos começam a surgir no cenário Organizacional.

Por fim, surge na década de 1970 a Psicologia do Trabalho. Sampaio (1998) apresenta que a nova postura da Psicologia do Trabalho

[...] a obsessão pela produtividade cede lugar para uma compreensão mais próxima do homem que trabalha. Isso implica um aumento do campo de visão do pesquisar em Psicologia do Trabalho, que, fazendo pesquisas menos instrumentais, consegue discutir temas que até então eram proibidos, esquecidos ou negligenciados. (p. 27) 
Deste modo podemos compreender que a Psicologia do Trabalho, pela primeira vez, apresenta como prioridade o trabalhador, com foco de análise voltado para as relações com o trabalho. Ainda acrescenta Sampaio (1998), que a Psicologia do Trabalho volta-se a pensar a saúde mental do trabalhador, suas relações com o campo e os significados atribuídos ao trabalho.

\subsection{CAMINHO DO ENSINO TÉCNICO NO BRASIL}

Este tópico irá percorrer, brevemente, os caminhos da educação técnica no Brasil, pois com este poderemos traçar e compreender os impactos que correspondem aos objetivos deste trabalho.

Segundo Ribeiro (1992), a história da educação Brasileira começa a partir da fase jesuíta da escolarização colonial com referências a conversão católica dos indígenas, precisando uma educação organizada, sendo o capitalismo mercantil o principal interesse da camada dominante portuguesa, ou seja, uma forma de poder e dominação.

Posteriormente Pereira et al. (2009) ressalta que, após os descontentamentos internos com a família real, em 1822, o Brasil conquista a Independência política de Portugal, assim em 1824, acontece a Primeira Constituição de obrigatoriedade do ensino primário ou básico que tomou amplitude no cenário nacional,

[...] em 1824 foi instituída a instrução primária para todo cidadão, em paralelo, o Estado procurava criar um tipo de ensino separado do ensino secundário e superior, objetivava a formação da força de trabalho que estava ligada à produção do país (GARCIA et al., 2018, p. 4)

Com isso Pereira et al. (2009, p. 3) afirmam que "entre 1800 a 1900, existia em torno das Casas Grandes, oficinas onde iniciou-se o Ensino Técnico." O ensino era voltado para a classe com menos recursos financeiros, pobres, surdos, mudos, para que aprendessem os ofícios do "Saber-fazer". Assim, em 1837, crianças e adolescentes menores de idade abandonados começaram a ser "treinados" (Pereira et al., 2009). Podemos dizer que o ensino obrigatório e técnico foi uma necessidade apresentada, devido ao cenário neste período de mão de obra no trabalho. 
Neste momento foram criadas algumas instituições de ensino de nível superior no país, como na Bahia, especificamente os cursos de economia (1808), curso de química (1817), englobando química industrial, mineralogia e geologia, em 1918, o curso de desenho técnico e no Rio de Janeiro o curso de agricultura (1814), dentre outros cursos que surgem com a necessidade no período para conhecimentos científicos e técnicos (RIBEIRO, 1992).

Com o avanço do mercado de trabalho, o campo educacional acaba refletindo o sistema de mão de obra para a produção, a necessidade do império seria suprida se todos, inclusive as crianças e adolescentes, participassem do sistema de alguma maneira, ou seja,

[...] a preocupação do Império em relação à busca da formação compulsória de trabalhadores em vários ofícios, porém o objetivo principal era retirar as crianças da rua para que não se transformassem em futuros desocupados, isso já era preocupação destas se tornarem um perigo para a sociedade. (GARCIA et al., 2018, p. 4)

De acordo com o contexto e o aumento de produção, ocorre a criação dos Liceus. Os autores Pereira et al. (2009) esclarecem que, as instituições eram destinadas ao ensino profissional, abrangendo os primeiros cursos técnicos, assim, os mesmos autores acrescentam que "O Estado assume o ensino para as camadas marginalizadas da população e algumas melhorias foram alcançadas: prédios e instalações melhores; currículo padronizado e material didático adequado." (p. 4)

Com o avanço no campo de trabalho e a necessidade de empregar trabalhadores, em 1940, os empresários começam a participar da educação técnica. Neste período surge o que denominou-se Sistema "S", como apresenta Cordeiro et al. (2009, p. 8) "Este sistema, composto pelos Serviços Nacionais de Aprendizagem relacionados principalmente a indústria e ao comércio (SENAI e SENAC)".

Segundo Pereira et al. (2009) o SENAl - Serviço Nacional de Aprendizagem Industrial-, que busca adaptar-se as necessidades empresariais e solucionar problemas de produção, gerar mão de obra. "[...] tinha como objetivo capacitar os "aprendizes", alunos com arco etário compreendidos ente 14 e 18 anos para serem 
posteriormente empregados na indústria" (CORDEIRO et al., 2009, p. 8). Enquanto o SENAC é fundado "[...] pelo Decreto-Lei $n^{\circ} .8 .621$, o Serviço Nacional de Aprendizagem Comercial, órgão que resulta da colaboração da iniciativa privada com o poder público [...]" (PEREIRA et al., 2009, p. 5), também tem objetivo de rendimentos com a iniciativa privada.

Assim, como apontam Cordeiro et al., (2009) ambos apresentam-se com um viés de atender aos objetivos empresariais, para suprir uma questão de qualificação da força de trabalho em constante expansão, portanto, refletia um desenho de formação profissional demandado por empresas atuantes nesse momento da história.

Após esse período o ensino técnico no Brasil tomou espaço na educação Brasileira. Segundo Garcia et al. (2018), escolas técnicas e profissionalizantes são levadas a nível de política pública, atendendo uma parcela da população com poderes aquisitivos - empresários - buscando sanar as necessidades do mercado financeiro para gerar lucro, com uma ascensão da economia brasileira.

Em 29 de dezembro de 2008, após debates, resultou na lei 11.892 que "Institui a Rede Federal de Educação Profissional, Científica e Tecnológica, cria os Institutos Federais de Educação, Ciência e Tecnologia, e dá outras providências." (BRASIL, 2008) A lei dispõe de formar profissionais que visam uma atuação e desenvolvimento econômico do país. Assim, podemos dizer que o ensino técnico está voltado em cada período às necessidades do país ao que diz respeito a geração de lucro.

\subsection{POSSÍVEIS DESDOBRAMENTOS}

Neste tópico será discutido, de forma breve, possíveis desdobramentos do cenário apresentado anteriormente, que diz respeito as formas de trabalho que muitos sujeitos foram submetidos, levando em consideração o percurso histórico de uma formação técnica, que diz sobre os objetivos deste trabalho.

Diante disso pode-se ressaltar que ao referenciar o mundo do trabalho, o sujeito trabalhador que possui a mão de obra, está envolvido no processo de trabalho, sendo 
que, por muitas ocasiões encontramos na história um trabalho executado que, por vezes, colocava o sujeito em posição de submissão, pois "O trabalhador trabalha sob o controle do capitalista, a quem pertence seu trabalho. O capitalista cuida em que o trabalho se realize de maneira apropriada e em que se apliquem adequadamente os meios de produção." (MARX, 2014, p. 219)

Diante do exposto pode-se ressaltar que, muitas vezes, alguns trabalhadores começaram a executar as tarefas muito cedo, enquanto crianças. Marx (2014) apresenta que o trabalho com as máquinas iniciado desde a infância, que de certa forma o faz pertencente ao objeto utilizado para a produção, máquina, que causa certa dependência ao ambiente de trabalho por estar envolvido diretamente neste processo, não enquanto apenas trabalhador, mas também uma máquina.

Assim, a forma de executar o trabalho encontra-se no campo de uma certa "técnica", que desde cedo, alguns sujeitos são colocados a aprender. Desta forma, o processo de trabalho torna-se, neste contexto muitas vezes, massificador e o trabalhador é colocado em uma posição de submissão que, segundo Weil (1996), "Da noite para o dia torna-se um suplemento da máquina, um pouco menos que uma coisa, e não se preocupam de forma alguma com que ele obedeça sob o impulso dos mais baixos motivos, contanto que obedeça" (p. 421). A questão neste contexto, é como a saúde mental do trabalhador sobrevive, diante desta existência do trabalho.

Estar envolvido nessas atividades, do trabalho, muitas vezes, produzem sofrimento, pois o trabalhador é impedido de agir de outras maneiras, que não estejam impostas, Clot (2006) afirma que a atividade do trabalho não é apenas o que foi feito, mas também o que não foi realizado, sendo essa atividade "impedida" de ser executada, podendo produzir sofrimento no ambiente de trabalho.

\section{RESULTADOS E DISCUSSÃO}

O trabalho assume diferentes significações ao decorrer da história. Em meio a tantos desdobramentos e diversas características, podemos dizer que, embora encontramos particularidades subjetivas nos significados do trabalho para os sujeitos, também 
percebemos que de, modo geral, para a existência de uma sociedade foi necessária uma "disposição" de conceber o trabalho como parte fundamental na construção de uma sociedade, cabendo a este assumir papéis cabíveis de acordo com a necessidade apresentada no contexto histórico.

Diante disso, muitas pessoas foram colocadas neste cenário para executar atividades do trabalho, crianças e adolescentes. Assim como referenciado anteriormente por Martins (2000) e Marx (2014), com isso podemos perceber que o trabalho impacta todas as estruturas sociais, produzindo movimentos de acordo com o contexto histórico, político e educacional a qual refere-se, ou seja, "todos" participam do trabalho de forma direta, produção, ou mesmo indireta, pois se o trabalho faz parte da construção social, nós somos a sociedade.

Muitas são as colocações que pairam sobre a função ideológica de trabalhar, dentre elas, uma questão que está ligada diretamente ao ócio provocado pela procrastinação, pois este dito é mencionado desde muito tempo como justificativa para trabalhar, pois como citado anteriormente por Gacia et al. (2018), a busca pela formação compulsória de trabalhadores é útil "[...] para que não se transformassem em futuros desocupados, isso já era preocupação destas se tornarem um perigo para a sociedade." (p. 4)

Percebe-se que este "perigo" citado acima está diretamente ligado a questão de produção/lucro para a sociedade, pois ao mesmo tempo em que este sujeito não está exercendo sua função de trabalhador, muitas vezes, é percebido como um "perigo". O "perigo" também se apresenta na produção que não acontece, no lucro para o empresário que não é o suficiente. Deste modo, por vezes, é necessária a frequentemente citada, "formação profissional".

Pois bem, apresenta-se neste momento a formação técnica como uma "salvação" para que, muitas vezes, os meio de produção continuem ativos, bem como para que a mão de obra qualificada continue sendo produzida.

O avanço no mundo do trabalho aparece de forma clara com o advento da revolução industrial, como apresenta Pochmann (2016), especificamente a terceira revolução, 
porém leva-se em consideração a importância imprescindível da primeira e da segunda revolução industrial, pois percebe-se crescimentos e necessidades de expandir conhecimentos e melhores condições humanas. Assim, com este parâmetro, pode-se ressaltar que esse marco provocou uma caminhada acelerada rumo as corporações e a busca empresarial, inicialmente, por qualificar os estudantes para o mercado que se apresentou.

A educação profissional iniciou-se, necessariamente, ligada aos interesses empresárias, assim com citado anteriormente por Pereira et al. (2009) e Cordeiro et al., (2009). O ensino técnico apresenta possiblidades de formar pessoas para exercer funções com necessidades de mão de obra qualificada, muitas vezes, barata. Diante deste contexto, desde as primeiras escolas técnicas, percebe-se que o ensino era destinado aos pobres e marginalizados, ou seja, pode-se analisar que o ensino técnico surge para a classe menos desfavorecida economicamente, será que pode-se supor que esse fato apresenta-se para que a mão de obra produzida pudesse ser barata? Eis uma reflexão que cabe nos dias atuais.

Portanto, pode-se dizer que o ensino técnico surge para cobrir interesses da elite empresarial do mercado financeiro, ou seja, o mercado empresarial desenhou os rumos da educação técnica brasileira. Com isso, pode-se supor grande impacto no mercado de trabalho, após a saída do estudante do ensino técnico, pois o ensino tecnicista, por vezes, limita o sujeito a ordem estabelecida, situação que pode produzir uma perda no sentido do trabalho que o sujeito também não encontra-se nesta produção, situação que pode causar um empobrecimento subjetivo.

Outra questão importante que pode-se ressaltar neste âmbito, em relação ao trabalhador, é sobre suas várias potencialidades e posições criativas diante de uma situação que, muitas vezes, são inibidas e impedidas de apresentar-se, pois não há estímulos positivos que o façam expor e explorar suas próprias possiblidades de outras tomadas de decisões dentro do ambiente. Ocasião que pode provocar uma privação do pensamento, logo, também é privado ao sofrimento. 
Neste contexto pode-se dizer que uma das possiblidades presentes para que este trabalhador tenha melhor qualidade de vida no ambiente de trabalho, encontra-se no trabalho produzido pela psicologia, pois embora essa ciência do conhecimento tenha entrado no campo do trabalho junto aos interesses das industrias, como citado anteriormente, na atualidade percebe-se que esse campo do conhecimento volta-se aos interesses na saúde do trabalhador e a vida que circula no ambiente de trabalho, produzindo uma via de relação tomada por significações do trabalho para o trabalhador.

Ressalta-se que, embora esse trabalho tenha apresentado os possíveis impactos do ensino técnico na formação profissional do estudante/ trabalhador, também compreende-se que mesmo nesse cenário o ensino técnico, muitas vezes, se apresenta como uma possiblidade de formação, para além do ensino regular, ou seja pode-se atribuir a essa formação grande número de inserção dos estudantes no mercado de trabalho, pois assume uma função social de empregabilidade que passou por muitas reformulações. Assim, pode-se inferir que o mercado de trabalho é tecnicista, ou seja, o ensino é tecnicista porque o mercado também é, ambos se alimentam um do outro.

Assim percebe-se que, embora haja uma valorização sobre o conhecimento técnico e o mercado de formação para tais fins, outro lado também existente, por vezes desfavorecido, é a desvalorização de outras forças de trabalho que também produzem o conhecimento, por outras vias, como as experiências do trabalhador. O quão rico é a produção do mercado de trabalho quando o trabalhador pode ser observado e requerido por suas potencialidades.

\section{CONCLUSÃO}

Este trabalho buscou apresentar alguns possíveis impactos da preparação do estudante no ensino técnico para o mercado de trabalho. Diante dos dados apresentados, através de uma revisão bibliográfica, pode-se observar alguns pontos relevantes que merecem destaque. 
Fica evidente a relação direta entre o mundo do trabalho e as formas de exploração e imposição do saber da classe dominante, sobre uma determinada cultura, junto ao período histórico em questão, pois as formas de exploração também aparecem mediante uma configuração social que propicia este acontecimento.

Com isso, também acrescenta-se que o trabalho, por vezes, selecionou e buscou encontrar, no meio social, mão de obra que pudesse executar determinadas funções a partir da qualificação profissional. Assim, o ensino técnico acabou tendo um papel social proposital e assertivo, principalmente em relação ao contexto em que foi criado. Destinou-se, inicialmente, a classe social menos favorecida economicamente e buscou apresentar uma função social para as pessoas que eram percebidas como "perigosas", ou seja, uma ideologia que aparece para "salvar" as pessoas referidas neste contexto.

Diante disso, será correto acrescentar que atualmente a situação referida ainda acontece? O ensino técnico seria destinado as classes menos favorecidas economicamente para explorar uma mão de obra barata e qualificada?

Diante do contexto apresentado, percebe-se uma relação entre a classe econômica dominante, empresários, e o surgimento das escolas técnicas. Assim, os impactos também poderiam ser referidos sobre as necessidades de exploração e regulação do conhecimento as restrições estabelecidas. Por meio desta reflexão, apresenta-se que os trabalhadores que passam por este processo, muitas vezes, restringe-se ao ensino técnico referido, não condicionado a reflexão, ou seja, segue os manuais técnicos colocados. Neste momento não culpabiliza-se o sujeito por esta condição, mas referese ao mundo do trabalho técnico constituído, assim como o ensino.

Importante salientar que o trabalho não pretendeu generalizar todos os estudantes que passaram por escolas técnicas, mas sim, apresentar, a partir de formulações e escritos históricos, possíveis impactos nos trabalhadores neste contexto, mesmo porque não pode-se deixar de referir-se ao ensino técnico como um campo de possiblidade de formação e empregabilidade. 
Com isso, uma questão importante seria apresentar, quais os meios e possibilidades neste contexto que poderiam ser modificados, visto que, a pesquisa não buscou esclarecer e nem mesmo fechar as portas para outras possíveis reflexões, mas pelo contrário, procurou deixar fendas para serem refletidas, pois entende-se a necessidade das portas continuarem abertas para futuros estudos, sobre os impactos da formação técnica de estudantes no mercado de trabalho.

\section{REFERÊNCIA BIBLIOGRÁFICA}

BRASIL. Presidência da República. Lei n. 11.892. Institui a Rede Federal de Educação Profissional, Científica e Tecnológica, cria os Institutos Federais de Educação, Ciência e Tecnologia, e dá outras providências. Brasília, DF. 2008. Disponível em: <http://www.planalto.gov.br/ccivil_03/_Ato20072010/2008/Lei/L11892.htm> Acesso em: 21 de março de 2020.

CLOT, Yves. A função Psicológica do trabalho. $2^{\circ}$ ed. Rio de Janeiro: Editora Vozes Ltda, 2006.

CORDEIRO, Lucas José; TRIZI, Ivan Amorin; ABUD, Bruno George. Inovações na gestão do Programa Estadual de Qualificação Profissional do Estado de São PauloPainel 18. II Congresso Consad de Gestão Pública. Brasília, 2009. Disponível em: <http:// consad.org.br/wp-content/uploads/2013/02/INOVA\%C3\%87\%C3\%95ES$\begin{array}{llll}\text { NAGEST\% } & \mathrm{C} & 3 \% & 83\end{array}$ DEQUALIFICA\%C3\%87\%C3\%83\%PROFISSIONALD O-ESTADO-DE S\%C3\%83OPAULO.pdf>. Acesso em: 03 de Abril de 2020.

GARCIA, Adilso de Campos; DORSA, Arlinda Cantero; OLIVEIRA, Edilene Maria de. Revista Vozes dos Vales. Educação profissional no Brasil: Origem e trajetória. UFMG. Minas Gerais. № 13, Ano VII, 2018. Disponível em: <www.ufvjm.edu.br/vozes>. Acesso em: 21 de Março de 2020.

MANCINI, Marisa Cotta; SAMPAIO, Rosana Ferreira. Quando o objeto de estudo é a literatura: estudos de revisão. Rev. bras. fisioter. São Carlos, v. 10, 2006. Disponível 
em: <http://www.scielo.br/scielo.php?script=sci_arttext\&pid=S1413 3555200600040 $0001 \&$ Ing =en\&nrm=iso >. Acesso em: 21 de março de 2020.

MARTINS, Sergio Pinto. Breve histórico a respeito do trabalho. Revista da Faculdade de Direito, Universidade de São Paulo, v. 95, p. 167-176. 2000. Disponível em: < http: //www.revistas.usp.br/rfdusp/ article / view/67461/70071>. Acesso em: 19 de Março de 2020.

MARX, Karl. O Capital: Crítica da economia política. Livro I: O processo de produção do capital. Trad. Reginaldo Sant' Anna, $24^{\circ}$ ed. Rio de Janeiro: Civilização Brasileira, 2006.

ORNELLAS, Thuê Camargo Ferraz de; MONTEIRO, Maria Inês. Aspectos históricos, culturais e sociais do trabalho. Rev. bras. enferm. Brasília, v. 59, p. 552-555, 2006. Disponível em: <http://www.scielo.br/scielo.php?script=sci_arttext\&pid=S0034-716 72006000400015 \& Ing=en\&nrm=iso>. Acesso em: 19 de março de 2020.

PEREIRA, Raquel da Silva; PALMISANO, Angelo; FARIA, Ana Cristina de; WIDMER, Gloria Maria; GONÇALVES, Andrea de Paiva. Ensino Técnico Profissionalizante: Formação Profissional e Cidadania. II Encontro de ensino e pesquisa em administração e contabilidade. Curitiba/PR. 15 a 16 de Novembro. 2009. Disponível em: < htt $p: / / w w$ w.a np a d.org.br/admin/pdf/EnEPQ331.pdf>. Acesso em: 22 de março de 2020.

POCHMANN, Marcio. Capitalismo e desenvolvimento. Brasil sem industrialização: a herança renunciada. Ponta Grossa: Editora UEPG, pp. 16-64, 2016. Disponível em: $\quad$ <http://books.scielo.org/id/yjzmz/pdf/pochmann-978857798216502.pdf>. Acesso em: 03 de Abril de 2020.

RIBEIRO, Maria Luíza Santos: História da educação brasileira: a educação escolar. $12^{\circ}$ ed. São Paulo: Editora Cortez: autores associados, 1992. 
SAMPAIO, Jáder dos Reis; Goulart, Iris Barbosa. ORG. Psicologia do trabalho e gestão de recursos humanos. In. Psicologia do trabalho em três faces, p. 19-40. São Paulo: Casa do Psicólogo, 1998.

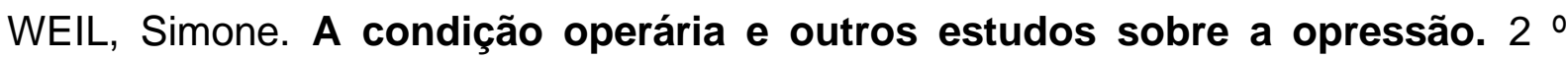
Edição, Rio de Janeiro: paz e Terra, 1996.

\section{APÊNDICE - REFERÊNCIA DE NOTA DE RODAPÉ}

3. Projeto aprovado pelo Comitê de Ética em Pesquisa conforme o protocolo $136 / 2020$.

Enviado: Junho, 2020.

Aprovado: Novembro, 2020. 